\title{
González Vera
}

\section{Alhué}

\author{
MI PADRE
}

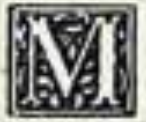

I padre comenzó a existir de improviso. Un dia lo vi junlo a la casa monlado en hermoso caballo. Nunca supe si era buen jinete; pero en ese inslante impresionaba su actilud. Sentiase alegre, irradiaba seguridad. Parecía un caballero de cuadro.

Era mi padre un hombre alto, blanco, de grandes ojos llameantes. Su traje negro hacialo aparecer casi delgado. Generalmente su aspecto era severo. pero cuando conversaba solia reirse con risa lenta, continuada y loca que lo transformaba en absoluto.

Hablaba con mucha seguridad y su voz estaba siempre variando de tono. Sin embargo, en un lapso cualquiera, sin suspender la charla. se iba intimamente de la conversación como solicilado por una preocupación parlicular.

En esa época creía yo que dentro de uno se alberga cierla alma inmorlal, y observando a mi padre, cuando daba la sensación de no eslar presente. sentia toda su realidad. Mientras hablaba daba casualmente con algún recuerdo significalivo y lo seguia. sin desatender la lógica de la conversación. Era un desdoblamiento perfecto.

Conversando mi padre se animaba en extremo. Todo lo que contaba parecia formar parle de su propia hisloria. Iba diciendo las palabras en el tono menor de la voz firme. Los delalles 
tenian esa vivacidad de lo experimentado. Uno veía paisajes, tipos, acción. IY con qué inteligente abandono intercalaba un espacio de silencio entre una frase $y$ otral

Más tarde he querido separar la parte de creación que habia en sus narraciones, pero no lo he conseguido.

Otro hecho fundamental de su carácler era la posición que ocupaba frente a los demás. Nadie lo tuteaba ni aventuraba en su presencia una familiaridad. A pesar de lo amable que eran sus maneras, por una razón que no pude comprender entonces. y que más tarde tampoco he descubierto. había en él algo inasible. Por hábito natural mantenía sus relaciones en la nota más fina.

Y esa misma actilud manlenía en nuestra casa. Mi madre sentia por él un emocionante respelo que le impidió siempre emplear el tú en vez del usted.

Durante muchos años debí ser para él algo asi como un arbusto. Mirábame de modo particularísimo y no me nombraba jamás. En cambio, yo le tenia más devoción que a Dios.

En casa estaba sólo a la hora del almuerzo. Duranle dos horas leia La Ley línea por linea, sin desdeñar ni siquiera los avisos.

Desde la habilación conligua, donde me instalaba para espiarlo, veíalo leer con abrumadora alención. Las letras del diario iban saltando una a una a sus ojos. Cuando su mirada caía sobre el pie de imprenta, arrojaba el papel y se levantaba para escobillarse con la mayor parsimonia:

\section{UNA CALLE}

Las calles del pueblo eran numerosas y anchas en demasia para el tránsito cotidiano.

A la hora del tren se abrian todas las puerlas y unas cuanlas personas salian con rumbo a la estación. Encontraban no sé qué placer en mirar, a través de las ventanillas, las cabezas desgreñadas de los viajeros. Para el pueblo. los hombres del tren formaban la humanidad desconocida pero latente. 
Antes y después las calles eran inútiles porque nadie las frecuentaba. Permanecian mudas, desiertas, escondidas. Eran puro paisaje. Y salir al balcón resultaba ocioso.

La nuestra era una calle de gran calma. En toda su extensión no había más de doce casas, pero los cercos coronados de hojas llegaban hasla donde alcanzan las miradas, y aún superaban esa distancia.

Por el hecho de nacer en la calle principal conservaba en su primera cuadra cierlo aliñamiento burgués: tenia aceras ripiadas $y$. de trecho en trecho, árboles anémicos, empolvados. sin primavera ni pájaros.

Después seguia una jornada de murallones clericales, y de repente la atravesaban los brazos de acero de la vía férrea, brazos fralernales si queréis, pero brazos que arrebatan desde la ciudad lejana el fruto de los campos.

Iba bajando luego con movimientos ondulantes hasta el cementerio. Su aspecio haciase selvático. Se alzaba a su derecha un bosque de álamos transparentes que favorecia con su sombra a los innumerables ociosos del pueblo. El flanco izquierdo estaba cubierto de zarzamora. Los conejos que ahí tenían su cuartel corrian bifurcándose entre la yerba.

Tristán, mientras permanecia el sol. los acechaba desde la alameda. Su escopeta tronaba hasta que no habia luz. Era el fantasma de los conejos.

Solia esparcir trozos de espejo junto a la zarza para atraerlos e inmovilizarlos; pero los conejos, seres sin vanidad ninguna, iban y venian locamente, zigzagueando.

Tan pronto como la obscuridad deshacía la calle, los raros transeuntes del dia desaparecian. Y hacian bien. A esa hora, las parejas que no querian llegar al matrimonio en estado de perfecia inocencia, buscaban el amparo del bosque.

Más allá comenzaba la zona del cementerio. La calle haciase de pronto anchurosa, como si los que por ahi transitaban necesitasen de mayor espacio.

Sin embargo, aparte del asno que poseía el Municipio. todos preferian irse por otro camino, porque un cementerio, aunque 
no tenga en su frontispicio coplas de Manriquez o inscripciones aterradoras, entenebrece todas las almas.

El asno era el único paseante venturoso. La proximidad del cementerio ponia entre él y sus enemigos una muralla de paz. Además en el contorno sobraba la yerba.

Frente al cementerio tenia su casa el viejo Aliste, sepulturero perpetuo ante quien nacian y morian las gentes después de acabar una vida sin asunto.

Un poco más lejos se asomaba el rancho de Cacú estrangulado por la zarzamora. Desde ahí seguia la calle sin la compañia de nadie. Y, naturalmente, aburrida de su propia soledad, se empinaba un tanto y saltaba al rio. Este se la llevaba consigo eternamente.

\section{CREPUSCULO}

La primera casa que habitamos, de fisonomia vagamente española, era demasiado grande. Al término de sus cuartos, un patio perennemente musgoso y siempre abandónado. la aislaba de la arboleda.

En la vastedad de ese albergue continuamente silencioso, yerto. inalterable. conoci todos los matices de la desesperación. Sentia deseos de huir, de trepar árboles, de gritar multitud de palabras, de oir otra voz. Después el aburrimiento roía lodos mis deseos, aplastaba mi cuerpo y me dejaba a tono con el ambiente.

Pero apenas el sol se hastiaba de estar sobre el pueblo, y las sombras de los árboles, las casas y los cuerpos se desprendian de esto para amalgamarse en la atmósfera, la alegría corria por la calle y golpeaba en nuestra puerta.

Los vecinos ponian los pisos en la acera y aguardaban la hora de cenar.

Las sombras iban pegándose circularmente y adensándose, y cuando ya el pueblo estaba encerrado. nos sentiamos como bajo la carpa de un circo.

El farolero del pueblo iba despertando las luces de nuestra 
calle. Qué gusto daba verlas temblar dentro de la obscuridad.

En la esquina inmediata estaba el Almacén El Tropezón... Una recia vara, pulida por el tiempo y el uso. servia a los huasos para atar sus cabalgaduras y topear en los dias festivos.

También el despachero aguardaba la noche. Apoyado en el mostrador miraba hacia la calle sin pestañear, con todos sus sentidos en tensión. A él no lo sorprendía asi no más el aliento de la noche. Mientras su vista percibia claramente la figura de las cosas ubicadas en el contorno, sentiase tranquilo: pero cuando se iniciaba la transfiguración y las formas individuales se sumaban en un todo inabarcable. desmesurado, recogia su mirada hasta el umbral y esperaba nerviosamente el arribo de la penumbra. Por solapado que fuera el avance de ésta, él no se dejaba engañar. Encendía las cuatro lámparas del negocio y la penumbra se esfumaba velozmente.

Los peones de los fundos circundantes entraban a beber. La calle se llenaba de palabras, risotadas y gritos.

También solian pasar algunas carretas. Sus astrosos conductores, perdidos en la obscuridad y subordinados al lentisimo tranco de los bueyes. cantaban tonadas de enervante monotonia.

Poco antes de la queda. llegaba hasta nuestra puerta un hombre trajeado de negro, bajo y de bondadosa barba amarillenta. A menudo me dejaba entre las manos un paquetito con frulas secas.

De día el Almacén El Tropezón tenía escaso movimiento. Entraban algunas personas antes del desayuno y cerca del almuerzo. En las demás horas no había sino tierra' y soledad.

Su dueño, don Nazario. sudaba angustia, porque aborrecia el silencio y carecia de iniciativa interior. Quizás le hubiera convenido más instalar una taberna en la ciudad; pero tampoco podía sufrir una situación nueva. Lo desconocido le horrorizaba. El no podía concebir nada: pero se aburría. 


\section{DON NAZARIO}

Don Nazario era altisimo... No terminaba nunca de ser grande. De sus hombros ya un poco cansados nacia el cuello, afianzado por gruesas venas, y sobre éste gravitaba una cabeza pequeña y canosa, de cuya cara, más pequeña aún, caía, sin desprenderse, una enorme nariz.

Era serio, perezoso monosilábico. Desde la mañana mordía su vieja pipa y tranqueaba por la acera de su almacén.

Le guslaba que los demás hablasen. Un charlatán impenitente era para èl un ser de gran inteligencia. La posibilidad de asociar varias palabras le maravillaba.

Sin embargo era absolutamente reacio a la elocuencia. Tal vez entendia las palabras; pero en su vida de relación no emitía más de cuatro.

Cuando necesitaba responder no decía sino asi. $\mathrm{Y}$ bastaba. Por el tono y el ademán podia deducirse lo que anhelaba.

Su mujer no se asomaba al mostrador casi nunca. Tenia el esquelelo muy escondido entre las carnes y el malhumor a flor de piel; pero tampoco hablaba. En su mímica cotidiana expresaba tanto la alegría como el disgusto.

Y precisamente en el mutismo residia la desventura conyugal.

Don Nazario, a pesar de hallarse tan cerca del cielo. era un hombre melancólico. Nunca lo abandonaba esa especie de tristeza carnal que vive y permanece en quien no ha conocido más mujer que la propia.

Solia aventurarse por las casas de las viudas. Pero era tan grande, tan mudo. Se asemejaba más a un árbol que a un hombre. Y luego no sabia decir esas palabras mágicas que afiebran la piel. Todo el deseo se le concentraba en sus ojos de brasas; pero su inmenso esqueleto, aislador de toda posibilidad romántica, ahuyentaba a las más valientes. Jamás se le aproximó el éxilo. Estaba condenado al abrazo frío de su mujer. de su mujer de tantos años. 
Alhué

En su condenada vida de almacenero no tenia más placer que escuchar. Sus grandes orejas le permitian enfocar los ruidos lejanos con perfecta claridad. Sabia cuándo el caudal del río era mayor y percibia el traquetraque del tren mucho antes que llegara a la eslación. En la noche oia ensimismado la plática de los peones. 